MagNetE workshop 2011

\title{
Hungarian repeat station survey, 2010
}

\author{
Péter Kovács ${ }^{\star}$, András Csontos, Balázs Heilig, András Koppán
}

Geological and Geophysical Institute of Hungary, Budapest, Hungary

Article history

Received October 17, 2011; accepted February 9, 2012.

Subject classification:

Main geomagnetic field, Instruments and techniques, Data processing, Global and regional models.

\begin{abstract}
The last Hungarian repeat station survey was completed between October 2010 and February 2011. Declination, inclination and the total field were observed using one-axial DMI fluxgate magnetometer mounted on Zeiss20A theodolite and GSM 19 Overhauser magnetometer. The magnetic elements of the sites were reduced to the epoch of 2010.5 on the basis of the continuous recordings of Tihany Geophysical Observatory. In stations located far from the reference observatory, the observations were carried out in the morning and afternoon in order to decrease the effect of the distant temporal correction. To further increase the accuracy, on-site dIdD variometer has also been installed near the Aggtelek station, in the Baradla cave, during the survey of the easternmost sites. The paper presents the technical details and the results of our last campaign. The improvement of the accuracy of the temporal reduction by the use of the local variometer is also reported.
\end{abstract}

\section{The Hungarian Repeat Station Network (HRSN)}

The network of geomagnetic observatories is sparse and uneven for providing detailed information on the spatial variation of the geomagnetic field, even in the characteristic wavelength representing the core field. It follows that in order to obtain a comprehensive model of the main field or also the crustal field in regional scale, network measurements have to be carried out filling the gaps in the spatial net of observatories.

In Hungary, the network campaign activities look back to a long history starting in 1847 , that is summarized in Szabó [1983] or in Kovács and Körmendi [1999]. From 1950, the spatial variation of the field is monitored periodically by national survey and repeat station (RS) networks. Until 1995, the country surveys have been carried out in 15 year periodicity with the occupation of 300 stations (in the 1950, 1965, and 1980 campaigns) or 195 stations (in 1994-95) distributed evenly over the $93,000 \mathrm{~km}^{2}$ area of Hungary. The Hungarian repeat station network (HRSN) was established in 1966 [Aczél and Stomfai 1969] consisting of 15 primary and $22 \mathrm{sec}$ ondary anomaly-free sites selected from the stations of the 1964-65 country network. Because of the increase of the artificial noise around and the demolition of some original
HRSN stations, our current RS network consists of only 13 sites, that is thought to be still enough for modeling the main field and updating the magnetic field obtained from country survey campaigns.

In 2003, HRSN joined MagNetE, which was initiated for harmonizing the network activities over Europe from the point of view of measurement standards and periodicity of campaigns.

In the following, technical details and basic results of our last RS campaign carried out in 2010 are presented. Then, the normal models and the normal annual change of the magnetic elements are shown based on the results of the last campaigns. In the vicinity of some stations dIdD type of portable variometer was operated during the last survey. The improvement in the temporal reduction accuracy of these stations due to the application of local variometer is shown in Section 4.

\section{Technical details and results of the last Hungarian repeat station survey}

The last Hungarian repeat station survey was carried out on 12 stations between October 2010 and February 2011 (Figure 1 and Table 1). The magnetic vector field was determined from the declination and inclination angles and the total field by the application of a DI Fluxgate magnetometer mounted on Zeiss Theo020A theodolite and an Overhauser type of GSM19 magnetometer, respectively. The angle components were measured according to the traditional zero-field method [Jankowski and Sucksdorff 1996]. In some stations, where the reference azimuth mark became invisible during the last decades, new reference direction had to be installed with the use of a pair of Ashtech MXII type GPS receivers.

For the majority of the stations the continuous recordings of the Tihany Geophysical Observatory were used for temporal reduction. The distance of the farthest station (Nagyszekeres, see Figure 1) from Tihany is $376 \mathrm{~km}$, while the biggest latitudinal and longitudinal deviations are $1.56^{\circ}$, and $4.72^{\circ}$, respectively. To decrease the error of the temporal reduction, a portable, suspended dIdD type variometer 


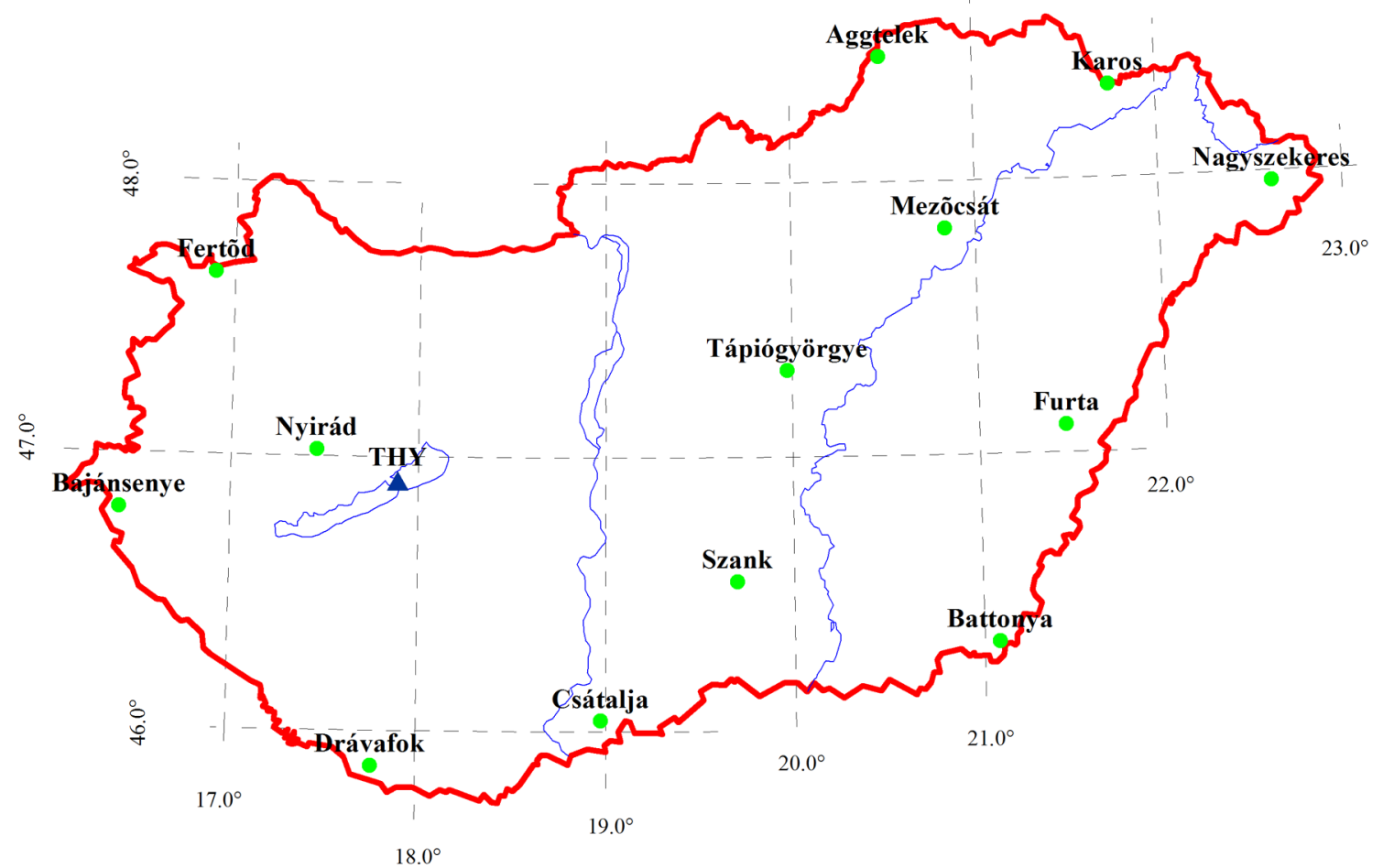

Figure 1. Locations of the Hungarian repeat stations and the reference observatory, Tihany (THY).

\begin{tabular}{|c|c|c|c|c|c|c|c|c|c|c|c|c|c|c|}
\hline \multirow[t]{2}{*}{$\begin{array}{l}\text { Repeat } \\
\text { station }\end{array}$} & \multirow[t]{2}{*}{ Nr. } & \multicolumn{2}{|c|}{$\begin{array}{l}\text { Geographic } \\
\text { coordinates }\end{array}$} & \multicolumn{5}{|c|}{$\begin{array}{c}\text { Magnetic components } \\
\text { on RSs, and Tihany (2010.5) }\end{array}$} & \multirow[t]{2}{*}{$\left|\begin{array}{l}\text { Number } \\
\text { of series }\end{array}\right|$} & \multicolumn{5}{|c|}{ Scatter } \\
\hline & & $\begin{array}{l}\Phi \\
\left({ }^{\circ}\right)\end{array}$ & $\begin{array}{c}\Lambda \\
\left({ }^{\circ}\right)\end{array}$ & D & $\begin{array}{c}\mathbf{H} \\
(\mathbf{n T})\end{array}$ & $\begin{array}{c}\mathrm{Z} \\
(\mathbf{n} \mathrm{T})\end{array}$ & I & $\begin{array}{c}\mathbf{F} \\
(\mathbf{n T})\end{array}$ & & $\begin{array}{l}\text { D } \\
(")\end{array}$ & $\begin{array}{c}\mathbf{H} \\
(\mathbf{n} T)\end{array}$ & $\begin{array}{c}\mathrm{Z} \\
(\mathbf{n T})\end{array}$ & $\begin{array}{c}\text { I } \\
(")\end{array}$ & $\begin{array}{c}\mathbf{F} \\
(\mathbf{n T})\end{array}$ \\
\hline Nyirád & 13 & 47.01833 & 17.46333 & $3^{\circ} 27.2^{\prime}$ & 21481.1 & 43101.1 & $63^{\circ} 30.6^{\prime}$ & 48157.0 & 4 & 8 & 2.0 & 1.1 & 7 & 0.1 \\
\hline Csátalja & 38 & 46.03971 & 18.97224 & $3^{\circ} 40.4^{\prime}$ & 21998.9 & 42652.1 & $62^{\circ} 43.0^{\prime}$ & 47990.4 & 8 & 13 & 2.3 & 0.9 & 10 & 0.4 \\
\hline Bajánsenye & 49 & 46.79853 & 16.40904 & $3^{\circ} 6.8^{\prime}$ & 21610.2 & 42901.5 & $63^{\circ} 15.9^{\prime}$ & 48036.2 & 10 & 2 & 1.5 & 1.2 & 8 & 0.5 \\
\hline Fertőd & 52 & 47.66483 & 16.89555 & $3^{\circ} 25.2^{\prime}$ & 21143.1 & 43431.8 & $64^{\circ} 2.6^{\prime}$ & 48304.2 & 6 & 7 & 1.8 & 0.9 & 9 & 0.2 \\
\hline Tápiógyörgye & 120 & 47.31548 & 19.97342 & $3^{\circ} 59.2^{\prime}$ & 21258.6 & 43523.0 & $63^{\circ} 58.0^{\prime}$ & 48436.9 & 11 & 20 & 4.2 & 1.3 & 19 & 0.6 \\
\hline Szank & 127 & 46.54547 & 19.69839 & $3^{\circ} 55.3^{\prime}$ & 21711.6 & 43054.3 & $63^{\circ} 14.3^{\prime}$ & 48218.3 & 13 & 51 & 0.8 & 0.7 & 4 & 0.7 \\
\hline Battonya & 145 & 46.31469 & 21.07999 & $4^{\circ} 9.2^{\prime}$ & 21796.6 & 42978.8 & $63^{\circ} 6.5^{\prime}$ & 48189.4 & 11 & 14 & 2.7 & 1.2 & 11 & 0.8 \\
\hline Furta & 159 & 47.10086 & 21.46354 & $4^{\circ} 16.6^{\prime}$ & 21393.5 & 43505.7 & $63^{\circ} 48.9^{\prime}$ & 48480.7 & 10 & 22 & 2.2 & 0.7 & 9 & 0.9 \\
\hline Mezőcsát ${ }^{\star}$ & 224 & 47.82553 & 20.83687 & $4^{\circ} 18.1^{\prime}$ & 20985.1 & 43837.7 & $64^{\circ} 25.2^{\prime}$ & 48601.0 & 6 & 28 & 1.0 & 1.1 & 5 & 0.8 \\
\hline Aggtelek ${ }^{\star}$ & 225 & 48.45559 & 20.49015 & $4^{\circ} 13.8^{\prime}$ & 20659.6 & 44156.4 & $64^{\circ} 55.6^{\prime}$ & 48750.1 & 9 & 16 & 2.4 & 1.3 & 11 & 0.8 \\
\hline $\operatorname{Karos}^{\star}$ & 254 & 48.33807 & 21.74217 & $4^{\circ} 36.8^{\prime}$ & 20708.9 & 44161.8 & $64^{\circ} 52.6^{\prime}$ & 48775.9 & 5 & 16 & 0.5 & 0.8 & 2 & 1.1 \\
\hline Nagyszekeres ${ }^{\star}$ & 284 & 47.96391 & 22.61887 & $4^{\circ} 37.0^{\prime}$ & 20852.4 & 44096.2 & $64^{\circ} 41.5^{\prime}$ & 48777.7 & 7 & 22 & 1.0 & 0.7 & 5 & 0.7 \\
\hline Tihany (OBS) & 300 & 46.90000 & 17.89166 & $3^{\circ} 31.6^{\prime}$ & 21528.0 & 43054.0 & $63^{\circ} 26.0^{\prime}$ & 48136.0 & - & - & - & - & - & - \\
\hline
\end{tabular}

Table 1. Definitive results of the 2010 repeat station campaign of Hungary, and the scatters of the observations. The magnetic component and the total field values are reduced to 2010.5. * The temporal reduction of the absolute measurements in the Aggtelek, Mezőcsát Nagyszekeres and Karos stations were carried out with the use of temporal variometer record.

was operated near the Aggtelek site during the occupation of the stations located in the biggest distances from Tihany (north-eastern part of Hungary). Moreover, to avoid considerable temporal magnetic variations during the observations the stations were occupied in the morning or afternoon periods. Both afternoon and morning observations were carried out in consecutive days in the stations located within a considerable distance from the reference observatory and 


\begin{tabular}{lccc}
\hline & $p_{\mathbf{0}}$ & $p_{1}$ & $p_{2}$ \\
\hline Declination (D) & $176.40(')$ & 0.11062 & 0.22092 \\
Horizontal intensity (H) & $22331.2(\mathrm{nT})$ & $-9.03251\left(\mathrm{nT} /{ }^{\prime}\right)$ & $-0.28607\left(\mathrm{nT} /{ }^{\prime}\right)$ \\
Vertical intensity (Z) & $42125.7(\mathrm{nT})$ & $9.38378\left(\mathrm{nT} / /^{\prime}\right)$ & $1.39605\left(\mathrm{nT} / /^{\prime}\right)$ \\
Inclination(I) & $3725.8(')$ & 0.86982 & 0.06126 \\
Total field (F) & $47655.9(\mathrm{nT})$ & $4.44508\left(\mathrm{nT} /{ }^{\prime}\right)$ & $1.13774\left(\mathrm{nT} /{ }^{\prime}\right)$ \\
\hline
\end{tabular}

Table 2. Coefficients of the first-order polynomial normal field models of the geomagnetic elements for Hungary obtained for the epoch of 2010.5 .

\begin{tabular}{|c|c|c|c|c|c|}
\hline \multirow[t]{2}{*}{ Repeat station } & \multicolumn{5}{|c|}{ Residuals } \\
\hline & $\mathbf{D}(')$ & $\mathbf{H}(\mathbf{n T})$ & $\mathrm{Z}(\mathrm{n} \mathrm{T})$ & $\mathbf{I}\left({ }^{\prime}\right)$ & $\mathbf{F}(\mathbf{n} T)$ \\
\hline Nyirád & -1.3 & 2.1 & 2.0 & -0.2 & 3.8 \\
\hline Csátalja & -1.0 & -11.2 & 26.4 & 1.9 & 12.4 \\
\hline Bajánsenye & 3.6 & 10.2 & -10.5 & -0.8 & -6.0 \\
\hline Fertőd & -2.6 & -0.5 & -12.2 & -0.5 & -9.8 \\
\hline Tápiógyörgye & 1.9 & 20.4 & -42.3 & -2.8 & -25.6 \\
\hline Szank & -2.9 & -10.5 & -30.2 & -0.3 & -31.1 \\
\hline Battonya & -0.0 & 5.8 & 31.1 & 0.5 & 30.6 \\
\hline Furta & 2.9 & -23.7 & -21.1 & 0.6 & -24.9 \\
\hline Mezőcsát & -2.1 & 2.7 & 2.4 & -0.2 & 5.4 \\
\hline Aggtelek & 1.8 & -7.3 & 9.4 & 1.0 & 0.6 \\
\hline Karos & -5.5 & -14.4 & 42.8 & 2.5 & 29.0 \\
\hline Nagyszekeres & 3.5 & 29.8 & -28.9 & -2.7 & -12.8 \\
\hline Tihany (OBS) & -0.8 & 12.0 & 18.3 & -0.2 & 22.5 \\
\hline Hurbanovo (OBS) & 2.6 & -15.4 & 12.8 & 1.2 & 5.9 \\
\hline
\end{tabular}

Table 3. Residuals between the 2010.5 model and measured magnetic elements at the repeat stations, and the Tihany and Hurbanovo observatories.

surveyed without the operation of portable variometer. Most of the measurements were carried out in quiet geomagnetic conditions exhibiting $\mathrm{K}_{\mathrm{p}}$ index between 0 and +2 . This condition was not satisfied at the Mezöcsát and Aggtelek stations (see Figure 1) where the measurements were disturbed by moderate geomagnetic storm of $\mathrm{K}_{\mathrm{p}}=+3$ and $\mathrm{K}_{\mathrm{p}}=4$ indices, respectively. However, for these stations the temporal reduction error could be diminished by the record of the portable variometer operating nearby.

In accordance with other European repeat station campaigns, each absolute observation was reduced to the epoch of 2010.5. For that, the 2010 annual means of the reference observatory, Tihany, were used. The obtained 2010.5 absolute values referred to the surveyed stations are reported in Table 1. According to the recommendation of MagNetE, the errors of the obtained magnetic elements are given in the form of scatter that is defined by the maximum absolute de- viation of the individual station observations from the averaged result. The maximum scatters in the 12 stations are 51", $4.2 \mathrm{nT}, 1.3 \mathrm{nT}, 19 "$, and $1.1 \mathrm{nT}$, for the D, H, Z, I magnetic components and the total field, respectively. The values are also listed in Table 1.

\section{Reference field and normal annual change of the mag- netic elements in Hungary}

In the practice of Hungarian geomagnetic surveys, the normal reference field is approximated by first- or secondorder polynomials of the geographic coordinates $(\Phi, \lambda)$. In the case of the repeat station campaigns, carried out in a sparse network of 12-13 stations, the normal model of the $B^{i}$ magnetic elements is determined according to first-order polynomial given in the form of:

$$
B^{i}(\phi, \lambda, \underline{p})=p_{0}+p_{1}\left(\phi-\phi_{0}\right)+p_{2}\left(\lambda-\lambda_{0}\right),
$$




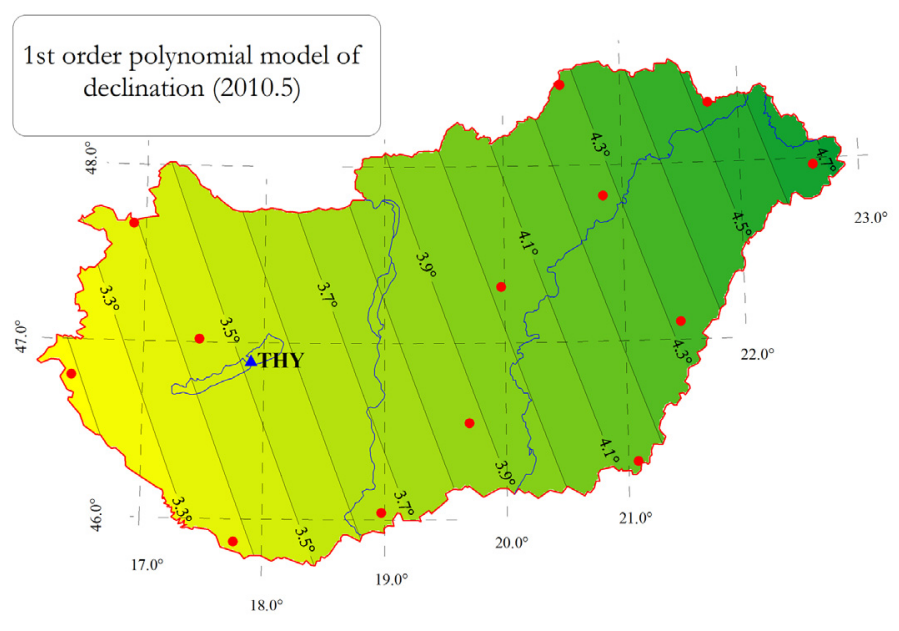

Figure 2. First order polynomial model of declination in Hungary for the epoch of 2010.5 .

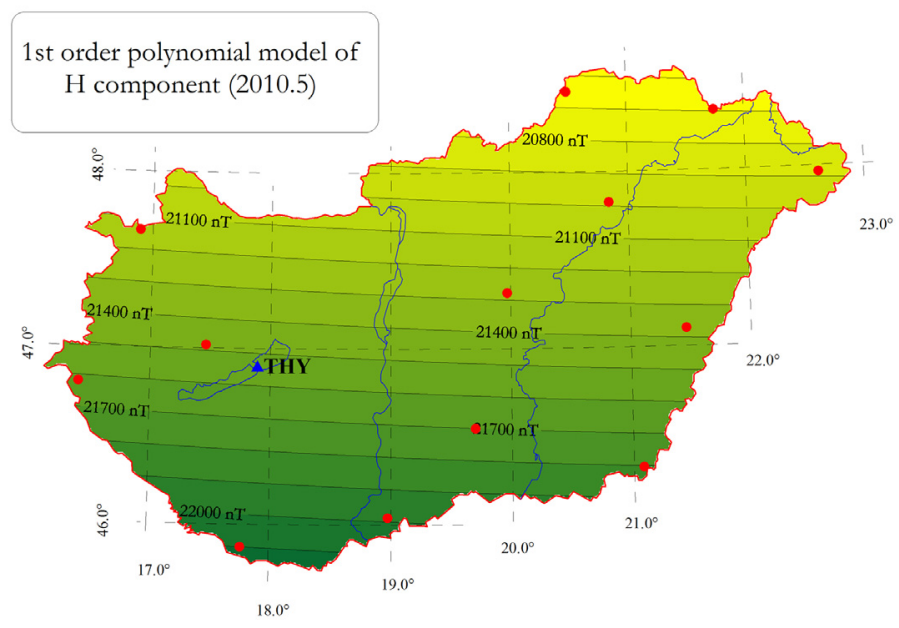

Figure 3. First order polynomial model of the horizontal intensity in Hungary for the epoch of 2010.5 .

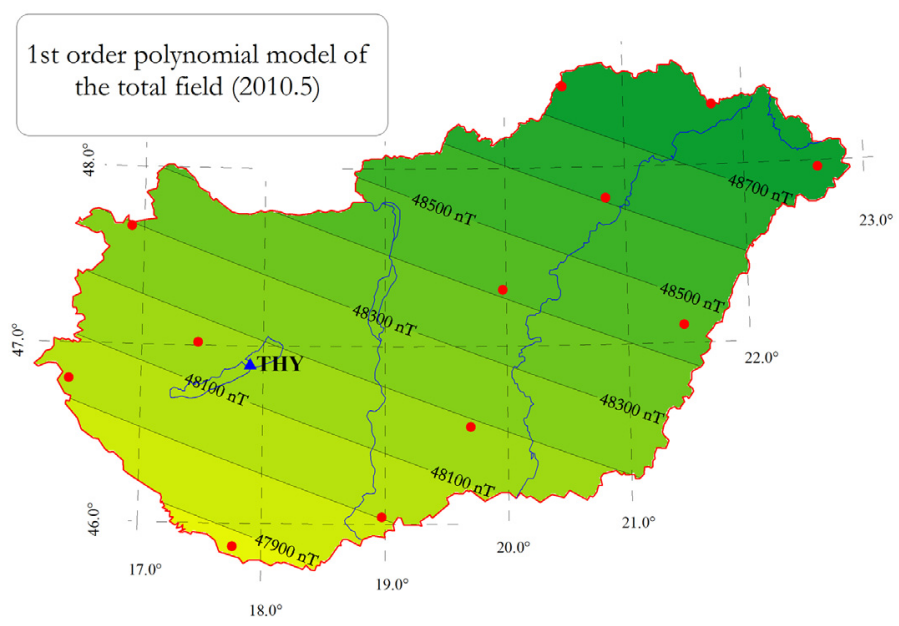

Figure 4. First order polynomial model of the total field in Hungary for the epoch of 2010.5 .

where $\phi_{0}=45.5^{\circ}$, and $\lambda_{0}=16.0^{\circ}$. The coordinates are inserted in minute units. The model coefficients, $p_{j}(j=0,1,2)$, are obtained by means of least-square fitting method. Beyond the magnetic elements of the repeat stations, the modeled data base includes the annual means of the Tihany and Hurbanovo (Slovakia) observatories from the year of the RS campaign.

For the epoch of 2010.5 , the obtained $p_{j}(j=0,1,2)$ model coefficients are listed in Table 2, while the differences between the measured and adjusted (normal) magnetic values, i.e. the residuals at the repeat stations and the observatories are reported in Table 3. The normal charts of the magnetic $\mathrm{D}, \mathrm{H}$, components and the total field are presented in Figures 2-4.

Note, that according to Bullard's equivalence rule [Bullard 1967] the first-order polynomial approximation over the area of Hungary corresponds to maximum spherical harmonic model degree of 128 , i.e. the smallest wavelength portrayed by the model is about $312 \mathrm{~km}$. It means that, beyond the core field, our normal model contain contribution from the crust.

We have also studied the normal annual change of the magnetic field elements, $\dot{B}^{l}$, over Hungary between consecutive campaign epochs. Similarly to the normal field, the annual change was modeled in the form of the first-order polynomial of the coordinates:

$$
\dot{B}^{\prime}(\phi, \lambda, \underline{q})=q_{0}+q_{1}\left(\phi-\phi_{0}\right)+q_{2}\left(\lambda-\lambda_{0}\right) .
$$

The model was fitted to the annual change of the field measured at the repeat stations and the observatories between consecutive epochs of RS campaigns. The obtained $q_{i}(i=0,1,2)$ model coefficients deduced for the periods of 2000.5-2003.5, 2003.5-2006.5, 2006.5-2009.0, 2009.0-2010.5 are listed in Table 4.

\section{Application of an on-site variometer}

During the survey of the Aggtelek, Karos, Nagyszekeres and Mezőcsát stations (see Figure 1) a suspended dIdD type variometer was operated near the Aggtelek site, in the Baradla cave. The cave environment ensured the thermal stability of the temporal observation. The variometer record started on November 9, 2010, at 08:05 a.m., and lasted until November 12, 2010, 09:50 a.m. Supposing that the geomagnetic variation was the same in the proximity of the variometer site, the bases of the variometer record were determined for any field element in each of the nearby repeat stations by absolute measurements. Consequently, temporary absolute magnetic records were referenced to the repeat stations occupied in the operational period of the portable variometer. The temporary observations lasting for more than three days enabled to deduce the field differences between the repeat stations and the reference observatory (i.e. Tihany) during quiet time periods [Newitt et al. 1996]. This condition could increase the accuracy of the reduction of the station observations to common epoch.

The difference $\mathrm{X}, \mathrm{Y}, \mathrm{Z}$ and $\mathrm{F}$ time-series measured between the magnetic variations of Tihany and the temporary record referenced to the Nagyszekeres station are shown in 


\begin{tabular}{|c|c|c|c|c|c|c|c|c|c|c|c|c|}
\hline & \multicolumn{3}{|c|}{$2000.5-2003.5$} & \multicolumn{3}{|c|}{$2003.5-2006.5$} & \multicolumn{3}{|c|}{$2006.5-2009.0$} & \multicolumn{3}{|c|}{$2009.0-2010.5$} \\
\hline & $q_{0}$ & $q_{1}$ & $q_{2}$ & $q_{0}$ & $q_{1}$ & $q_{2}$ & $q_{0}$ & $q_{1}$ & $q_{2}$ & $q_{0}$ & $q_{1}$ & $q_{2}$ \\
\hline Declination & 5.09 & 0.00108 & -0.00027 & 4.78 & 0.00179 & -0.00055 & 6.13 & 0.00276 & -0.00144 & 7.39 & -0.00133 & 0.0003 \\
\hline Horizonthal Int. (H) & 7.8 & -0.00524 & -0.014 & 13.7 & -0.00859 & -0.00735 & 14.4 & -0.00614 & -0.01087 & 7.4 & -0.01836 & -0.01466 \\
\hline Vertical Int. (Z) & 37 & 0.00759 & -0.00689 & 27.3 & -0.00618 & 0.00285 & 26.1 & 0.00754 & 0.00302 & 31.5 & -0.00353 & 0.01278 \\
\hline Inclination & 0.75 & -0.00013 & 0.00062 & 0.04 & -0.00018 & 0.00053 & -0.03 & 0 & 0.00078 & 0.61 & 0.00056 & 0.00112 \\
\hline Total field (F) & 36.3 & 0.00778 & -0.0122 & 30.3 & -0.00759 & -0.00066 & 30 & 0.00288 & -0.00192 & 30.5 & -0.00635 & 0.00527 \\
\hline
\end{tabular}

Table 4. Coefficients of the first-order polynomial normal annual change of the secular variation of the geomagnetic elements for Hungary in periods between consecutive repeat station campaigns. The unit of $q_{0}$ is min./ year and $\mathrm{nT} /$ year for the angular and intensive components, respectively. $q_{1}$, and $q_{2}$ is given in $1 /$ year for $\mathrm{D}$ and $\mathrm{I}$, while in $\mathrm{nT} /$ (year ${ }^{\star}$ min.) for $\mathrm{H}, \mathrm{Z}$ and $\mathrm{F}$ components.
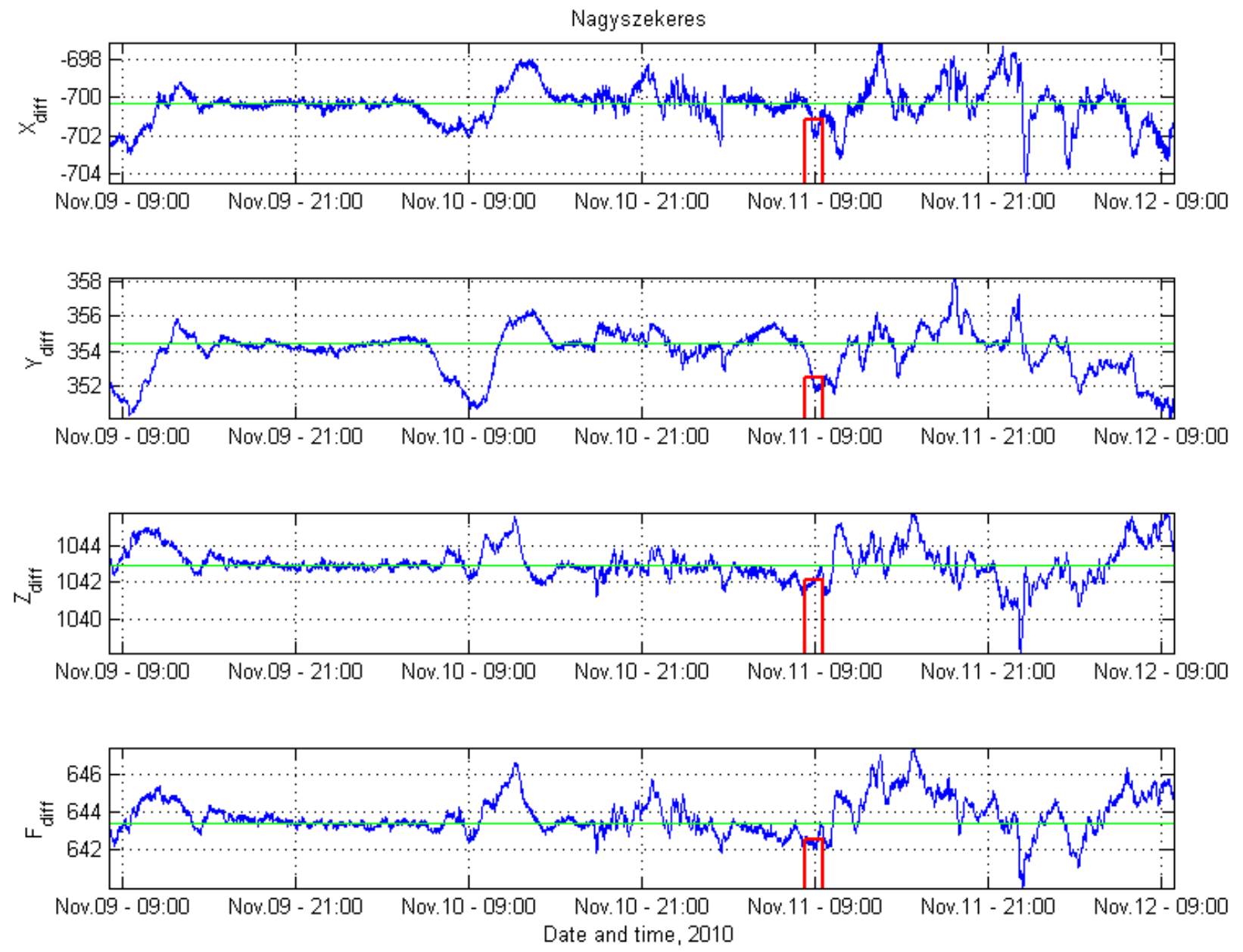

Figure 5. X, Y, Z magnetic component and total field difference time series between Tihany and Nagyszekeres station. Nagyszekeres component data were obtained from the variation recorded at Aggtelek (Baradla-cave) and absolute measurements made at Nagyszekeres. Green lines represent the quiet time means of the differences, while the red columns show the period of the RS measurements in Nagyszekeres station.

Figure 5. We also present the temporal variations of the standard deviations computed in 60 minutes of sliding-window sequences of the difference time-series (Figure 6). The two figures evidence that the most stable difference values are exhibited during the evening-night-morning period of November 9-10, and the late afternoon period of November 10. Later, a medium geomagnetic storm started with maximum $\mathrm{K}_{\mathrm{p}}$ index of five (see bottom panel of Figure 6) that resulted in stronger variability in the difference time-series of the Tihany and Nagyszekeres records.
The definitive values of the $\mathrm{X}, \mathrm{Y}, \mathrm{Z}$, and $\mathrm{F}$ differences were computed from those parts of the difference time-series where the measured standard deviations were less than $0.2 \mathrm{nT}$ for each component. The mean difference values computed with this condition are indicated by green lines in the graphs of Figure 5.

In Table 5 the maximum absolute displacement of the difference geomagnetic time-series from the quiet-time mean differences are listed for the three consecutive days represented by different geomagnetic activity. In quiet magnetic 

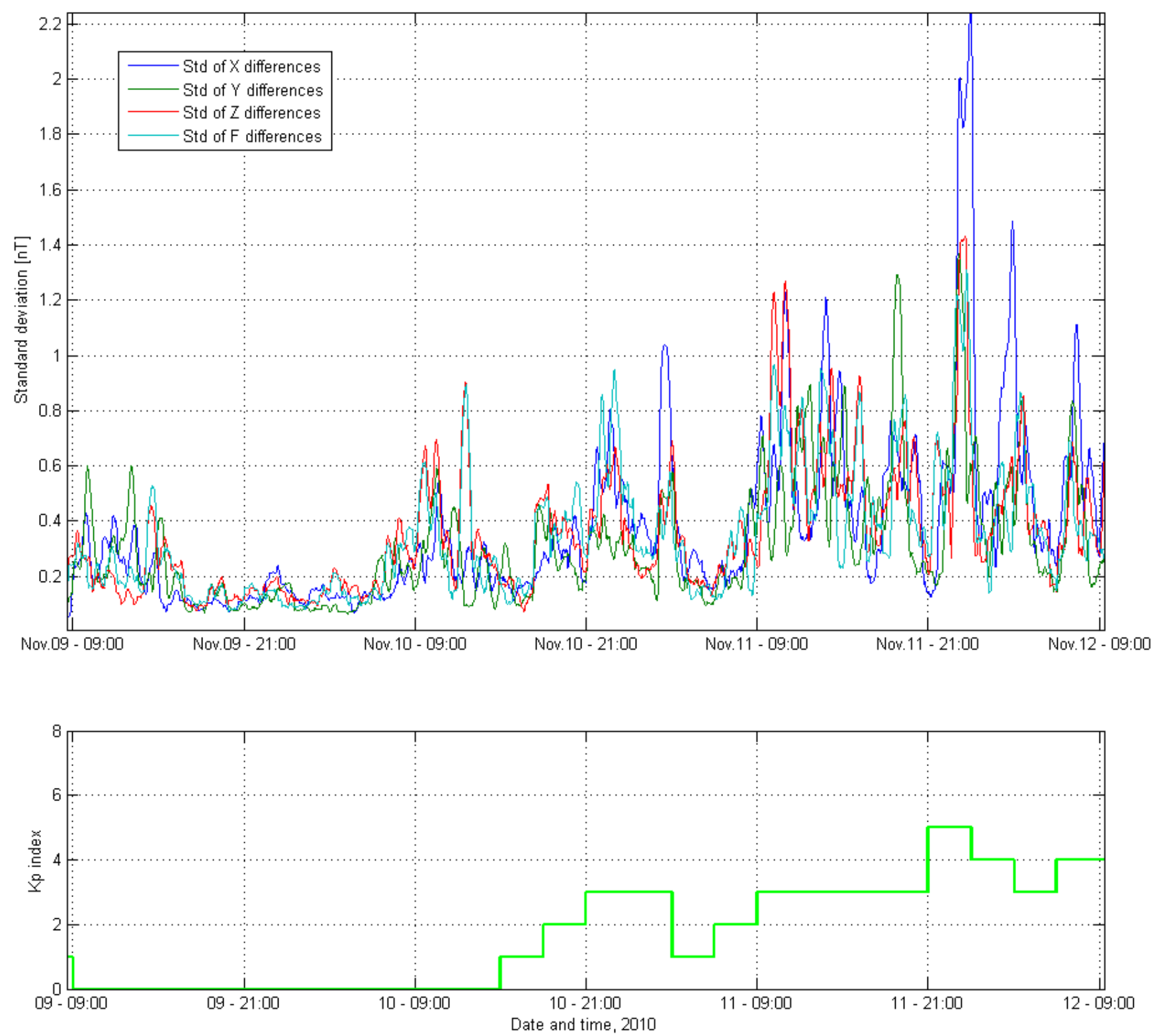

Figure 6. Temporal variation of the standard deviation of the difference time-series plotted on Figure 5 (top), and the variation of the planetary Kp index (bottom).

conditions the biggest possible displacement appear in the $\mathrm{Y}$ component, while during the storm the three components and the total field exhibit about the same absolute deviations (3.8-4.8 $\mathrm{nT}$ ) from the means. It is also shown that the medium magnetic storm on November 11 could increase the expected displacements by a factor of about 1.5 .

Note that the difference magnetic time-series referred to the four stations occupied during the operation of the dIdD

\begin{tabular}{lccccc}
\hline Date & $\begin{array}{c}\Sigma \\
\mathbf{K p}\end{array}$ & $\begin{array}{c}\mathbf{X} \\
(\mathbf{n T})\end{array}$ & $\begin{array}{c}\mathbf{Y} \\
(\mathbf{n T})\end{array}$ & $\begin{array}{c}\mathbf{Z} \\
(\mathbf{n T})\end{array}$ & $\begin{array}{c}\mathbf{F} \\
(\mathbf{n T})\end{array}$ \\
\hline 2010.11 .09$. & 4 & 2.6 & 4.1 & 2.1 & 1.9 \\
2010.11 .10$. & 6 & 2.3 & 3.7 & 2.7 & 3.2 \\
2010.11 .11 & 24 & 4.1 & 3.8 & 4.7 & 4.0 \\
\hline
\end{tabular}

Table 5. Maximum absolute deviations of the difference geomagnetic timeseries of Tihany and Nagyszekeres (Figure 5) from the quiet-time means, in three consecutive days represented by different geomagnetic activity. variometer differ from each other by constant base differences. It means that the quiet periods, as well as the displacements of the magnetic trends from the quiet-time means (i.e. the values in Table 5) are independent from the RS location.

Thus, it is suggested that the values listed in Table 5 can refer to the lower limits of the possible errors that could appear in the time-reduction of the easternmost repeat stations during previous campaigns carried out without the application of on-site variometer. It should be emphasized that in the computation of these errors the difference between the geomagnetic variation at the portable dIdD site and the nearby repeat stations were not considered.

For the case of the last campaign the period of the reoccupation of the Nagyszekeres station are indicated by red columns in the graphs of Figure 5. The heights of the columns represent the averages of the component differences between Nagyszekeres and Tihany observatory in the period of the absolute measurements. Consequently, the de- 


\begin{tabular}{|c|c|c|c|c|c|c|c|c|c|c|c|c|c|c|}
\hline & \multirow[t]{2}{*}{\begin{tabular}{|l} 
Day of meas. \\
in Nov. 2010
\end{tabular}} & \multirow[t]{2}{*}{$\begin{array}{l}\text { Kp. } \\
\text { ind. }\end{array}$} & \multicolumn{3}{|c|}{$\begin{array}{c}\text { Diff. in X comp. between } \\
\text { THY and RS (nT) }\end{array}$} & \multicolumn{3}{|c|}{$\begin{array}{c}\text { Diff. in Y comp. between } \\
\text { THY and RS (nT) }\end{array}$} & \multicolumn{3}{|c|}{$\begin{array}{l}\text { Diff. in } Z \text { comp. between } \\
\text { THY and RS (nT) }\end{array}$} & \multicolumn{3}{|c|}{$\begin{array}{c}\text { Diff. in total field between } \\
\text { THY and RS (nT) }\end{array}$} \\
\hline & & & $\begin{array}{l}\text { During } \\
\text { reocc. }\end{array}$ & $\begin{array}{l}\text { Quiet } \\
\text { time }\end{array}$ & $\Delta$ & $\begin{array}{l}\text { During } \\
\text { reocc. }\end{array}$ & $\begin{array}{l}\text { Quiet } \\
\text { time }\end{array}$ & $\Delta$ & $\begin{array}{l}\text { During } \\
\text { reocc. }\end{array}$ & $\begin{array}{l}\text { Quiet } \\
\text { time }\end{array}$ & $\Delta$ & $\begin{array}{l}\text { During } \\
\text { reocc. }\end{array}$ & $\begin{array}{l}\text { Quiet } \\
\text { time }\end{array}$ & $\Delta$ \\
\hline Aggtelek -1 & 09 & 0 & -886.0 & -884.7 & 1.3 & 197.2 & 199.6 & 2.4 & 1104.3 & 1102.4 & -1.9 & 615.4 & 614.1 & -1.3 \\
\hline Aggtelek - 2 & 12 & 4 & -886.5 & -884.7 & 1.8 & 196.4 & 199.6 & 3.2 & 1104.6 & 1102.4 & -2.2 & 615.9 & 614.1 & -1.8 \\
\hline Karos & 10 & 0 & -847.1 & -846.2 & 0.9 & 338.4 & 341.8 & 3.4 & 1107.7 & 1107.8 & 0.1 & 639.7 & 639.9 & 0.2 \\
\hline Nagyszekeres & 11 & $2-3$ & -704.1 & -703.2 & 0.9 & 352.3 & 354.1 & 1.8 & 1041.6 & 1042.2 & 0.6 & 640.9 & 641.7 & 0.8 \\
\hline Mez csát & 11 & 3 & -561.7 & -562.0 & -0.3 & 249.7 & 250.0 & 0.3 & 784.5 & 783.7 & -0.8 & 466.8 & 465.0 & -1.8 \\
\hline
\end{tabular}

Table 6. Differences of the magnetic elements (X, Y, Z, F) between the repeat stations and Tihany observatory (1) measured during the reoccupations of the stations and (2) referred to quiet-time period with the use of on-site variometer record. $\Delta$ means the difference between the two determinations, i.e. the potential error of the time-reduction carried out without on-site variometer record.

viation of these values from the quiet-time means (green lines) represent the errors that would have been emerged in the temporal reduction of the magnetic elements in the case of lacking the local variometer records. The potential errors of the time-reductions of the three Cartesian magnetic components and the total field are summarized in Table 6 for Nagyszekeres and the other three stations.

\section{Summary}

The technical details and the results of the last Hungarian repeat station campaign carried out between October 2010 and February 2011 have been reported. The normal model of the magnetic field and its secular variation was also presented for the epoch of 2010.5 and for the periods between consecutive past Hungarian RS campaigns, respectively. The models were defined in plane coordinate system by the first-order polynomials of the geographic latitude and longitude. Note that the polynomial fit does not satisfy the curl-free property of the magnetic field in the case of the lack of electric currents, and does not consider the curvature of the Earth over an extended area. For this reason, to define the reference field in a regional scale, the polynomial fit has to be substituted by spherical harmonic analyses. Currently, the adjusted spherical cap harmonic analysis [De Santis 1992] was applied for the determination of joint reference magnetic field of Croatia and Hungary [Kovács et al. 2011]. It is intended to extend this analysis over larger area by inclusion the RS data of neighboring countries.

In the 2010 campaign, portable dIdD on-site variometer was operated in the vicinity of the easternmost Hungarian repeat stations in order to increase the accuracy of the temporal reductions. During the variometer record moderate geomagnetic storm occurred. It was shown that the profit of the application of the on-site variometer in the time-correction depended on the geomagnetic activity of the period of reoccupation. It is suggested that the differences between corrections carried out with and without the use of the onsite variometer record represent the potential errors of time-reductions of previous campaigns in the north-eastern part of Hungary.
Acknowledgements. The work was supported by the National Innovation Office, Hungary, and by the Ministry of Science, Education and Sport of Croatia. We thank the Aggtelek National Park for the permission to install our portable variometer in the Baradla cave. The Hurbanovo Observatory is also acknowledged for providing their 2010 annual means for the computation of the Hungarian normal field models.

\section{References}

Aczél, E., and R. Stomfai (1969). The variations of the geomagnetic elements according to the secular measurements in the year 1966, Geofizikai Közlemények, 18 (1/2), 3-11 (in Hungarian with English summary).

Bullard, E.C. (1967). The removal of trend from magnetic surveys, Earth Planet. Sci. Lett., 2, 293-300.

De Santis, A. (1992). Conventional spherical harmonic analysis for regional modeling of the geomagnetic field, Geophys. Res. Lett., 19 (10), 1065-1067.

Jankovski, J., and C. Sucksdorff (1996). Guide for magnetic measurements and observatory practice, IAGA, Warsaw.

Kovács, P., and A. Körmendi (1999). Geomagnetic repeat station survey in Hungary during 1994-1995 and the secular variation of the field between 1950 and 1995, Geophysical Transactions, 42 (3/4), 107-132.

Kovács, P., E. Vujic, A. Csontos, M. Brkic, B. Heilig and A. Koppán (2011). Regional magnetic field model for Croatia and Hungary, $6^{\text {th }}$ Congress of Balkan Geophysical Society, ext. abstract published in earthdoc.org.

Newitt, L.R., C.E. Barton and J. Bitterly (1996). Guide for Magnetic Repeat Station Surveys, International Association of Geomagnetism and Aeronomy, Boulder, Colorado, USA

Szabó, Z. (1983). The magnetic declination and its variation in Hungary between 1850-1980, Geodézia és Kartográfia, 35 (6), 436-442 (in Hungarian with English summary).

\footnotetext{
*Corresponding author: Péter Kovács,

Geological and Geophysical Institute of Hungary, Budapest, Hungary; email: kovacs.peter@mfgi.hu.
}

(C) 2012 by the Istituto Nazionale di Geofisica e Vulcanologia. All rights reserved. 